\title{
EFFEGTS OF SOME TRANQUILLIZING AGENTS ON BRAIN NORADRENALINE AND DOPAMINE LEVELS OF SHOGKED RATS
}

\author{
TETSUO SATOH, TAKIO IWAMOTO AND YUKIKO TOKUMITSU \\ Institute of Chemical Pharmacology, Faculty of Pharmaceutical Sciences, \\ Hokkaido University School of Medicine, Sapporo
}

Received for publication September 2, 1963

In the previous report (1), the authors showed that the brain noradrenaline level in rat was induced to elevation, in the state of electric shock, compared with that in non-treatcd animals. On the other hand, pretreatment with some tranquillizing agents, chlorpromazine, azacyclonol inhibited the increase of noradrenaline level in shocked state, while, chlordiazepoxide had no effect on noradrenaline level.

In addition to the previous paper, other tranquillizing agents, tetrabenazine, thioridazine and cyproheptazinc* were employed in this experiment in order to examine their effect on both noradrenaline and dopamine levels of rat brain in abnormal environment, i.e., electrically shocked state.

\section{MATERIALS AND METHODS}

The experimental animals employed here were male inbred Wistar albino rats weighing $220-300 \mathrm{~g}$ fed with standard Oriental rat food (Oreintal Yeast Co.). Rats fasted from 18 to 24 hours before cxpcriment were sacrificed by decapitation and whole brains were immediately removed and placed in dry-icc as soon as possible, and then brains were treated as before (1).

The techniques of extraction and purification of noradrenaline and dopamine were carried out according to the method described by Bertler $(2,3)$, and catecholamine levels in eluates were determined fluorometrically as described by Weil-Malherbe and Bone's technique (4) or Euler and Floding's method (5).

In the column method cmployed here, differential estimation of noradrenaline and dopamine in various samples was performed by utilizing the difference in the concentration of the hydrochloric acid in elution. Drugs were administered subcutaneously 1 hour prior to shock in each condition.

\section{RESULTS}

As shown in previous paper (1), brain noradrenaline level of shocked rats was predominantly incrcased compared with that in non-treated animals, when rats without drug 


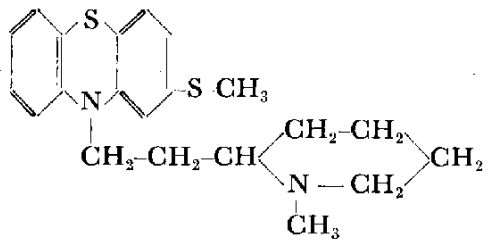

Thioridazine

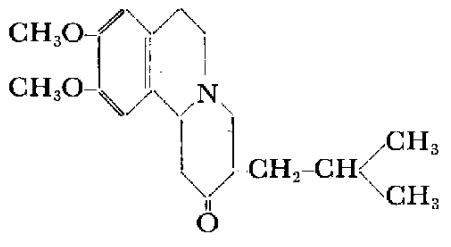

Tetrabenazine

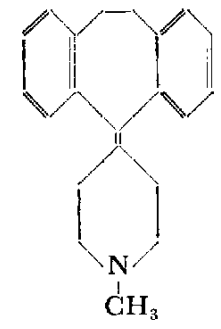

Cyproheptazine

FIG. 1. The chemical structures of tranquillizing drugs employed.

TABLE 1. Effects of cyproheptazine, tetrabenazine and thioridazine on rat brain noradrenaline level.

\begin{tabular}{lcccc}
\hline & Control & CY & TB & TH \\
Noradrenaline $(\mu \mathrm{g} / \mathrm{g})$ & $1.09 \pm 0.133^{*}(6)$ & $1.16 \pm 0.263(5)$ & $0.37 \pm 0.145(5)$ & $0.83 \pm 0.222(5)$ \\
Mean effect & - & $+0.09 \pm 0.193$ & $-0.72 \pm 9.129$ & $-0.27 \pm 0.246$ \\
$\mathbf{P}$ & - & N.S. & 0.01 & N.S. \\
\hline
\end{tabular}

Figures in parentheses are the number of animals cmployed.

* Mean \pm standard error of the mean.

CY : Cyproheptazine $10 \mathrm{mg} / \mathrm{kg}$, s.c.

TB : Tetrabenazine $10 \mathrm{mg} / \mathrm{kg}$, s.c.

TH : Thioridazine $3 \mathrm{mg} / \mathrm{kg}$, s.c.

All drugs were administered 1 hour prior to the beginning of shock.

TABIL 2. Effects of electric shock on brain dopamine level.

\begin{tabular}{lcc}
\hline Condition & Mean \pm SEM & P \\
\cline { 2 - 3 } Normal & $0.49 \pm 0.11(16)$ & - \\
Shocked & $0.83 \pm 0.22(10)$ & $<0.05$ \\
\hline
\end{tabular}

SEM : standard error of the mean.

Figures in parentheses are the number of animals employed.

administration were used as control animal.

Dopamine level in rat brain was incrcased by electric shock (Table 2). Table 1 and 3 summarizcd the effccts, of various tranquillizing drugs used in the present study, on the noradrenaline and dopamine levels in shocked brains.

The administration of tetrabenazinc induced marked inhibition of an increase in noradrenaline level caused by electric shock, however, the other drugs, cyproheptazine and thioridazine had no effects on rat brain noradrenaline and dopamine levels in shocked state.
TABLE 3. Effects of tranquillizing agents on shocked rat brain dopamine level.

\begin{tabular}{lccc}
\hline \multicolumn{1}{c}{ Drugs } & Mean \pm SEM & $\mathrm{P}$ \\
\hline Control & $0.74 \pm 0.18$ & $(6)$ & - \\
Chlorpromazine & $0.46 \pm 0.11$ & $(4)$ & $<0.05$ \\
Tetrabenazine & $0.47 \pm 0.20$ & $(4)$ & N.S. \\
Azacyclonol & $0.40 \pm 0.16$ & $(6)$ & $<0.05$ \\
Thioridazine & $1.06 \pm 0.35$ & $(5)$ & N.S. \\
Cyproheptazine & $0.76 \pm 0.51$ & $(5)$ & N.S. \\
Chlordiazepoxide & $0.51 \pm 0.13$ & $(4)$ & N.S. \\
\hline
\end{tabular}

SEM : standard error of the mean. 


\section{DISCUSSION}

The possible relationship between the tranquillizing effect of drugs employed here and catccholamine levels of rat brain in the single administration of drugs, was not always comparablc.

Reports on the tranquillizing effect of chlorpromazine have been obtained by many investigators; one of them shows that chlorpromazine has no effect on brain catecholamine levels in physiological condition (6), and another shows that chlorpromazine attacks the hypothalamus, especially adrenergic region (7).

On the other hand, chlorpromazine attacks the receptor site of noradrenaline in reticular formation, consequently, it shows the competitive antagonism for noradrenaline. As shown by Yamaguchi, the death of rabbit due to electric shock was obscrved within several hours, in contrast, the pretreatment with chlorpromazine in the shocked state, was found to suppress the severe behaviors of animal (8). Chlorpromazinc causes a functional deficiency of brain noradrenaline by antagonizing central adrenergic mechanisms (9).

In addition, Pletscher reported that chlorpromazine showed the sedative action associated with loss of noradrenaline (10), and both reserpine and chlorpromazine were thought to depress central sympathetic activity, but Bogdanski et al. (11) demonstrated that the two drugs exerted entirely different action on central autonomic activity.

These conclusions are based on the illustration that the effects of reserpine and lacrimation are due to a decreased central sympathetic activity, while the autonomic effects of chlorpromazine are due largely to decreased sympathetic output.

According to the literatures cited above and our results, a few hypothescs are posturated.

I. The reasons for elevation of catecholamine levels caused by electric shock are assumed as follows :

1. MAO activity is inhibited by electric shock as well as MAO inhibitor such as iproniazid, with which it causes central excitation in animal, as a result of MAO blockade, frec noradrenaline is responsible for excitation.

2. Once blood-brain barrier is attacked by electric shock and its permeability to catecholamines is altered, catecholamines are transported into ccntral nervous system from peripheral pooling site, consequently, animals are induced to excitation.

II. The mechanism of inhibiting cffect of tranquillizing agents on the increase of catecholamine levels in shocked state may be due to the alteration of permeability of granule membrane to noradrcnaline and dopaminc.

Though some speculations are proposed under these experimental conditions, further precise experiments are required to establish the ultimatc conclusions.

\section{SUMMARY}

The effects of some tranquillizing agents on rat brain catecholamine levels were studied. 
1. Tetrabenazine inhibited the elevation of noradrenaline level in shockcd state, in contrast, cyproheptazine and thioridazine were ineffective on noradrenaline level in this respect.

2. Chlorpromazine and azacyclonol induced the inhibition of the elevation of dopamine level of rat brain in shocked state, however, tetrabenazine, thioridazine, cyproheptazine and chlordiazepoxide showed no significant inhibition.

Acknowledgement: This work partially supported by the Grand-in-Aid for Scientific Research from the Ministry of Education, which is gratefully acknowledged.

\section{REFERENCES}

1) Iwamoto, T. And Sato, T. : Tilis Journal 13, 66 (1963)

2) Bertlar, A. : Acta physiol. scand. 44, 273 (1958)

3) BER'TLler, A. : Ibid. 44, 293 (1958)

4) Weil-Malherbe and BONe : Biochem. J. 58, 132 (1954)

5) Euler, U.S. V. AND FloDlyg, I. : Acta physiol. scand. 33, suppl. 118, 45 (1955)

6) Carlsson, A. : Pharmacol. Rev. 11, 490 (1959)

7) Biradley, P.B. And KeY, B.J. : Pharmacol. Chemother. 14, 340 (1959)

8) Yamaglchi, Y. : Folia Endocrinol. Japon. 131, 380 (1955)

9) KILLAM, E.K. : Psychopharmacology, p. 21, Natl. Acad. Sci. Natl. Gouncil Publ., Washington D.C. (1959)

10) Pleźtscher, A., Beskndorf, H. and Gey, K.F. : Science 129, 844 (1959)

11) Bogdanski, D.F., Sulser, F. And Brodie, B.B. : J. Pharmacol. 132, 176 (196I) 